\section{Vol. 66, No. 21}

In "Notifiable Diseases and Mortality Tables," on pages ND403-22, weekly case counts were inadvertently omitted from the tables "Provisional cases of selected* infrequently reported notifiable diseases $(<1,000$ cases reported during the preceding year) — United States, week ending May 27, 2017 (21 st week) ${ }^{\dagger}$ " and "Provisional cases of selected notifiable diseases $(\geq 1,000$ cases reported during the preceding year), and selected* low frequency diseases, United States and U.S. territories, weeks ending May 27, 2017, and May 28, 2016 (21st week). ${ }^{\dagger}$ The updated Week 21 tables can be found at https://wonder.cdc.gov/ and at https://data.cdc.gov/.

\section{Vol. 66, No. 22}

In the report "Japanese Encephalitis Surveillance and Immunization - Asia and Western Pacific Regions, 2016," on page 581, in the table "Characteristics of Japanese encephalitis (JE) surveillance in countries with JE virus transmission risk, 2016," and on page 582, in the table "Characteristics of Japanese encephalitis (JE) immunization programs in countries with JE virus transmission risk, 2016," Taiwan should have been indented beneath China. The corrected tables with added indents can be found at http://apps.who.int/iris/ bitstream/10665/255639/1/WER9223.pdf. 